CORRIGENDUM

doi:10.1038/nature 10220

\title{
Thermal history of Mars inferred from orbital geochemistry of volcanic provinces
}

David Baratoux, Michael J. Toplis, Marc Monnereau

\& Olivier Gasnault

Nature 472, 338-341 (2011)

An error in the calculation of heat flow contours drawn in Fig. 4 of our Letter was drawn to our attention by J. Ruiz (Universidad Complutense de Madrid). A surface temperature of $200^{\circ} \mathrm{C}$ was mistakenly used instead of the correct temperature of $220 \mathrm{~K}$. With the stated value of thermal conductivity $\left(3.5 \mathrm{~W} \mathrm{~m}^{-1} \mathrm{~K}^{-1}\right)$, heat flows are about $20 \%$ higher than those originally shown. The knock-on effect of this fact is that the calculated Urey ratio is $20 \%$ lower than stated, but still comfortably above the terrestrial value. On the other hand, we note that the value of thermal conductivity relevant to planetary mantles is not well constrained, with preferred values covering the range 2.5 to $4 \mathrm{~W} \mathrm{~m}^{-1} \mathrm{~K}^{-1}$ (ref. 1). A value of $3.0 \mathrm{~W} \mathrm{~m}^{-1} \mathrm{~K}^{-1}$ and the correct surface temperature leads to calculated heat flow very similar to those shown in our original Fig. 4. A corrected version of Fig. 4, using a surface temperature of $220 \mathrm{~K}$ and a conductivity of $3.5 \mathrm{~W} \mathrm{~m}^{-1} \mathrm{~K}^{-1}$, is shown below.

Figure 4 has also been corrected in the original HTML and PDF.

1. Breuer, D. \& Moore, W. B. in Treatise of Geophysics Vol. 10, 299-341 (Elsevier, 2011).

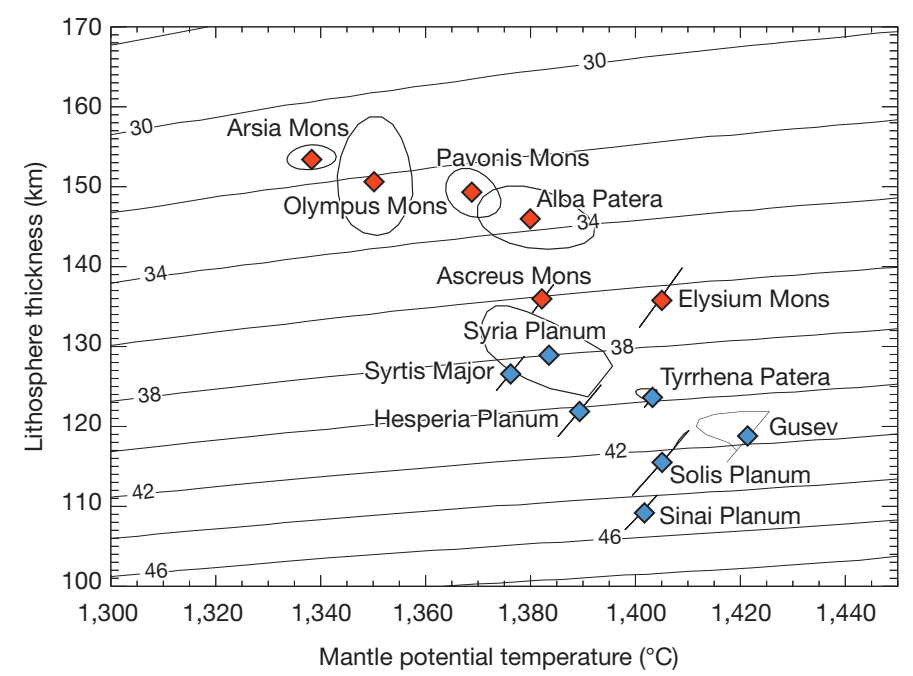

